\title{
Vegetable and Corn Yields in the United States, 1900-Present
}

\author{
A.E. Tiefenthaler ${ }^{1}$ and I.L. Goldman ${ }^{2}$ \\ Department of Horticulture, University of Wisconsin-Madison, 1575 Linden Drive, Madison, WI 53706 \\ W.F. Tracy ${ }^{3}$ \\ Department of Agronomy, University of Wisconsin-Madison, 1575 Linden Drive, Madison, WI 53706
}

During the 20th century, gains in crop yields can be attributed to the application of technologies such as irrigation, soil fertility enhancement, crop storage practices, chemical means of controlling pests and disease, and mechanization of most aspects of production (Acquaah, 2002; Harlan, 1992; Tilman et al., 2001). These gains can also be attributed to the work of plant breeders who strive to produce more desirable, higher yielding crops with the ability to resist pests and adverse climatic conditions (Allard, 1999). In maize, improved production practices and breeding have contributed equally to crop yield gains in the past (Duvick, 1984). Data regarding the relative contribution of improved management and improved genetics in vegetable crops are lacking.

The average U.S. maize yield was $\approx 1630 \mathrm{~kg} \cdot \mathrm{ha}^{-1}$ from the $1860 \mathrm{~s}$ through the 1930s [U.S. Dept. of Agriculture (USDA),1900-2000]. Corn yield began an upward trend in the late 1930s, but the average yield of field corn for the decade of the 1930s was still only 1524 $\mathrm{kg} \cdot \mathrm{ha}^{-1}$. The average yield for the $1990 \mathrm{~s}$ was $7839 \mathrm{~kg} \cdot \mathrm{ha}^{-1}, 5$ times the yield of the 1930s. A number of researchers have studied the basis for this increase by partitioning the contributions of improved genetics from those of improved management. Systematic studies performed by Duvick (1992) on corn hybrids grown from 1930 to 1989 in central Iowa demonstrated a linear increase in yield for the duration of this time period. An equivalent of $56 \%$ of the annual average gain in Iowa corn yields for this period was determined to be attributable to the genetic improvements of these hybrids (Duvick, 1984, 1992). It is clear from Duvick's studies that much of the genetic change is represented by increased inputs and stress associated with high input intensive management systems. Modern corn is much more resistant to drought stress associated with high population densities $(30,000$ plants/ha, 1930s; 80,000 plants/ha, 1980s) (Duvick, 1999). High levels of nitrogen fertilizer increases stalk lodging in grain crops. Modern corn is more resistant to stalk lodging than corn from the 1930s. High population densities also increase stalk lodging. Thus, in corn genetic changes were required for optimum use of increased inputs and higher population densities.

In order to carry out comparative studies, seed of cultivars representing different eras must be obtained, planted, and evaluated under controlled conditions at a number of location $\times$ year combinations. The experiment should include multiple production practices, reflecting current management practices as well as older practices. Such studies have been conducted in a number of agronomic crops [soybean (Glycine $\max$ L. Merrill), Specht and Williams, 1984; barley (Hordeum vulgare L.), Wycham and Rasmusson, 1983; sorghum (Sorghum bicolor L. Moench), Miller and Kebede, 1984], and in most cases large portions of the overall yield gain have been attributed to progress from plant breeding. However, Douches et al. (1996) found little influence of genetic improvement in the large increases in potato (Solanum tuberosum L.) yields in the United States since the 1920s. Those workers found most of the gains from breeding programs during this period were associated with early maturity and improved tuber appearance. Thus, the primary reason yields increased was likely improvements in production practices.

Received for publication 15 July 2002. Accepted for publication 31 Dec. 2002.

${ }^{1}$ Former Undergraduate Student.

${ }^{2}$ Associate Professor; to whom reprint requests should be addressed. Phone: (608) 262-7781; fax: (608) 262-4743: e-mail address: ilgoldma@facstaff.wisc.edu ${ }^{3}$ Professor.
Few vegetable crops have been evaluated over different eras in controlled experiments. This lack of information means that overall yield trends for many vegetable crops are not known. With this in mind, we evaluated crop yield data for onion (Allium cepa L.), carrot (Daucus carota L.), potato, snap bean (Phaseolus vulgaris L.), pea (Pisum sativum L.), table beet (Beta vulgaris L.), sweet corn (Zea mays L.), field corn, and alfalfa (Medicago sativa $\mathrm{L}$.) for both Wisconsin and the United States during the 20th century. The goal of this survey was to compare vegetable crop yields with those for field corn during the 20th century. Wisconsin Agricultural Statistics bulletins compiled by the Wisconsin Statistical Reporting Service were used in determining the yields of all vegetable crops except sweet corn and potato from 1900 to the present. USDA bulletins were used for national field corn, sweet corn, and potato yield data over the same time period.

Wisconsin, in 1992, devoted $23.4 \%$ of its land for the production of vegetables, corn, and other grain crops, a figure much larger than the $14.9 \%$ of acreage used for such crops nationally (USDA Agricultural Statistics, 1998). For more than 100 years, Wisconsin has been a national leader in vegetable production for the processing industry (Stare, 1949), which has included onion, carrot, potato, snap bean, pea, table beet, and sweet corn. The carrot, potato, snap bean, pea, table beet, and sweet corn crops usually rank Wisconsin in the top five nationally in terms of production quantity (Wisconsin Agricultural Statistics, 1999). In addition, the large dairy industry in the state requires significant alfalfa and field corn acreage. Wisconsin leads the United States in the production of corn for silage and is usually among the top 10 states in the production of corn for grain and hay (Wisconsin Agricultural Statistics, 1999). The importance of these vegetable and grain crops to the agriculture of Wisconsin makes it an ideal state for a case study to compare vegetable and grain crop yields.

Compared to all other vegetable crops, potato yields have increased most dramatically over the last 40 years in both Wisconsin and the United States (Fig. 1). The average potato yield in Wisconsin from 1900 to 1910 was $6208 \mathrm{~kg} \cdot \mathrm{ha}^{-1}$ per year, a number that steadily increased to an average of $39,235 \mathrm{~kg} \cdot \mathrm{ha}^{-1}$ per year for 1990 to 1997 . Despite this nearly 7 -fold yield gain, Douches et al. (1996) did not find that genetic progress was responsible. They suggested these large increases may have been due to superior management practices, such as nitrogen fertilization, which became widespread in potato production in the 1940s (Tilman et al., 2001) just when potato yields began to increase dramatically (Fig. 1).

A large portion of U.S. potato production remains dependent on a single cultivar. The potato cultivar known as 'Russet Burbank' was developed in the 19th century and has been the dominant cultivar in U.S. potato production for many decades. Due to the dominance of 'Russet Burbank', which is vegetatively propagated, yield gains must have been due to factors other than breeding, as suggested by Douches et al. (1996). While improved pest control is probably a major factor affecting higher potato yields, soil fertility, especially nitrogen, must have played a large role as well. It is interesting that potato cultivars developed in the 19th century are able to tolerate very high nitrogen fertility. In grain crops, high nitrogen fertility can result in increased vegetative growth and stalk lodging, which reduces harvestable yield, especially in mechanized systems. Pre-1940s cultivars of corn and small grains lodge severely when modern nitrogen levels are applied. In response to increased nitrogen inputs, corn breeders concentrated on improving stalk and root strength. Similarly, breeders of the green revolution wheat and rice cultivars introduced semi-dwarf cultivars 

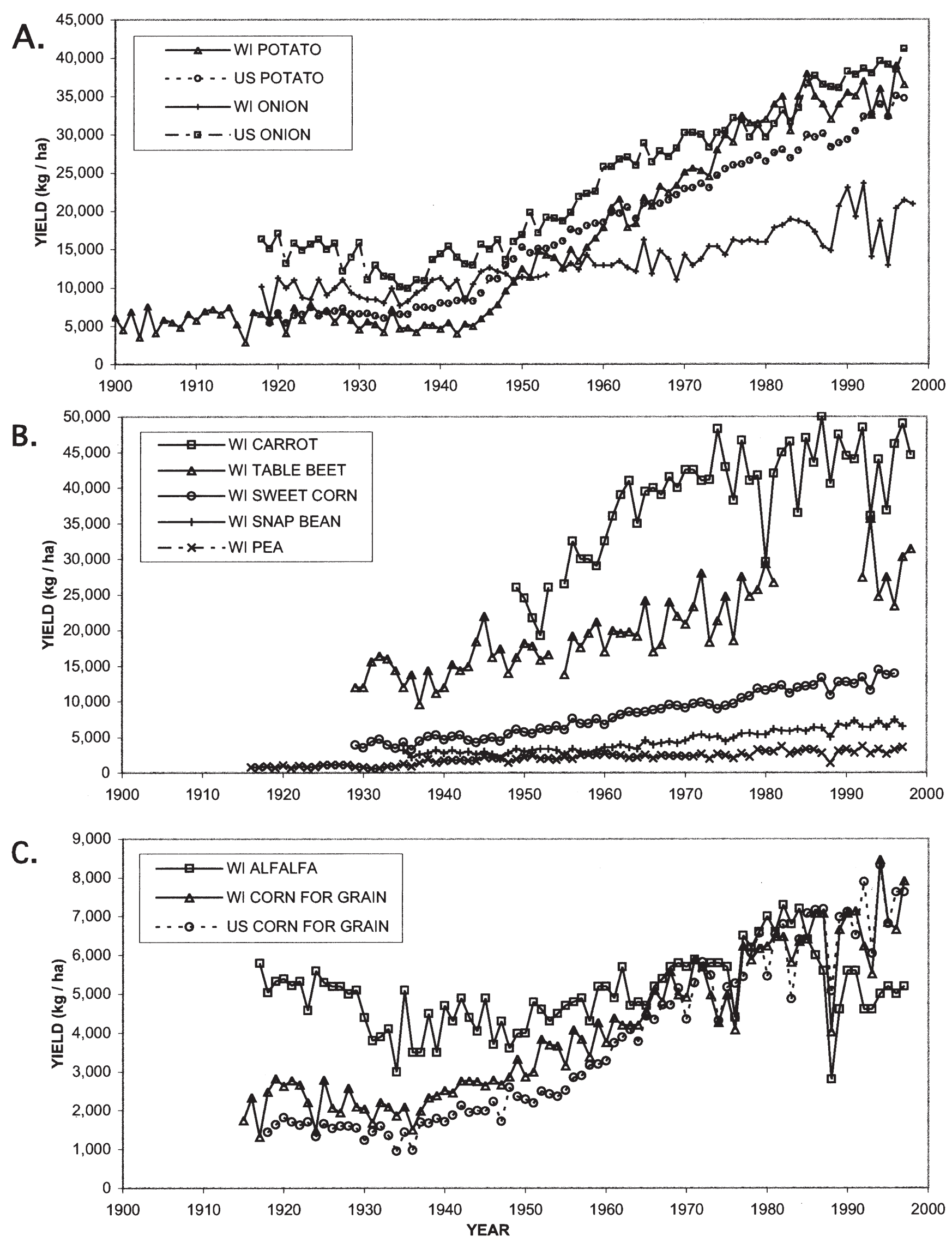

Fig. 1. Yields of potato, onion, carrot, table beet, sweet corn, snap bean, pea, alfalfa, and corn in the United States and Wisconsin during the 20th century. (A) Comparison of potato and onion yields in the United States and Wisconsin from 1900 to 1998. (B) Vegetable crop yields in Wisconsin from 1916 to 1998.

(C) Alfalfa and corn yields from 1916 to 1998. 
with short straw and reduced stalk lodging even at high nitrogen levels. The key difference in potato may be that the harvestable biomass is below ground and the stems do not have the same physical demands required to hold up the harvestable portion of the crop. Thus, cultivars developed prior to the era of high nitrogen inputs benefit from modern fertility levels.

In contrast to potato yields, alfalfa yields have not increased for the duration of the 20th century and hold at a production level averaging $5643 \mathrm{~kg} \cdot \mathrm{ha}^{-1}$ per year (Fig. 1C). Alfalfa breeders routinely select for multiple pest resistance, which may inhibit yield gains (Hill et al., 1988). In addition, modern alfalfa production does not include the large nitrogen inputs that are commonplace in vegetable crops such as potato. Also, current management recommendations for alfalfa emphasize increased feed value (quality) over increased yield (Undersander et al., 1994). Evidence indicates that as feed value increases, alfalfa yield decreases (Undersander et al., 1994).

An approximate 2-fold increase in yield was noted for onion, table beet, snap bean, and carrot beginning in the 1920s, 1930s, 1930s, and 1950s, respectively. Carrot yield approximately doubled between 1950 and 1975 , a rate of increase similar to that of potato and field corn and slightly more than sweet corn over the same period. But unlike the other crops, carrot yields leveled off in the 1970s and showed no improvements through the end of the century. Since carrots, like potato, have their yield below ground, it would be instructive to study the nitrogen inputs applied to these crops over the last half of the 20th century. Pea and sweet corn yields increased about 3-fold from 1915 and 1930 to 1999 , respectively. While these yield increases are substantial, they do not approach the magnitude of increase measured for potato (7-fold) or field corn (5-fold).

It is well known that vegetable breeders do not select primarily for yield, but rather focus on quality factors such as shape, texture, flavor, color, and storability (Wehner, 1999). For example, the reduction of sugars in potatoes has dramatically increased the ability to use these potato cultivars for chipping. Carrot cultivars of today contain significantly higher carotenoid levels than those of the 1920s, thereby contributing more to Vitamin A nutrition than in the past (Simon, 2000). On the contrary, field corn breeders select for yield as a primary trait and have achieved spectacular success during the 20th century (Duvick, 1999). The target goal of the field corn breeder is yield of kernels at a defined moisture level, a fact that must make breeding for yield much more efficient. By contrast, vegetable crops are defined by their high moisture content, and therefore yield measurements are difficult to standardize across environments and market classes.

The large difference in yield increase between field corn and certain vegetable crops may be explained partly by the number of workers in these crops. Breeding efforts, as measured by the number of scientific person-years (SYs) involved in breeding activities for a given crop and year, indicate 389 SYs for vegetable breeding and $1505 \mathrm{SY}$ s for agronomic crops in U.S. public and private sectors combined in 1994 (Frey, 1996). Of these agronomic crop SYs, 545 were devoted to breeding field corn. There were 32 SYs for sweet corn and fewer than 20 SYs for any one vegetable crop examined in this study (Frey, 1996). Data such as these verify far greater efforts at improving corn than vegetable crops in the United States. However, breeding effort alone cannot explain the yield trends. There were 68 alfalfa SYs in the survey by Frey (1996) and yet alfalfa exhibited no yield increase during the 20th century.

Results from this survey indicate that yield gains in vegetable crops, such as onion, carrot, snap bean, pea, sweet corn, and table beet, have exhibited 2-to 3 -fold increases during the 20th century, while potato yields have increased nearly 7 -fold. In contrast to these vegetables, forage alfalfa yields during the 20th century have not risen at all, suggesting no effect of breeding on increasing yield. Field corn yields have risen at a lower rate than potato ( $\approx 5$-fold $)$, with an estimated $50 \%$ of that response due to breeding. However, as discussed previously, breeding progress has had little to do with increases in potato yields. No data exist for contribution of plant breeding to yield of the vegetable crops studied herein; however, such data would be of great use retrospectively to inform future breeding efforts. If breeding is not the primary determinant of such trends in the vegetable crops, production practices must explain a significant portion of these realized yield gains. The role of breeding in improving crop yields seems worthy of further consideration.

\section{Literature Cited}

Acquaah, G. 2002. Principles of crop production. Prentice Hall, New Jersey.

Allard, R.W. 1999. Principles of plant breeding. 2nd ed. Wiley, New York.

Douches, D., D. Maas, K. Jastrzebski, and R.W. Chase. 1996. Assessment of potato breeding progress in the USA over the last century. Crop Sci. 36:1544-1552.

Duvick, D.N. 1984. Genetic contributions to yield gains of U.S. hybrid maize, 1930-1980,p. 15-47. In:W.R. Fehr(ed.). Genetic contributions to yield gains of five major crop plants. CSSASpec. Publ.
7. ASA-CSSA-SSSA, Madison, Wis.

Duvick,D.N. 1992. Genetic contributions to advances in yield of U.S. maize. Maydica. 37:69-79.

Duvick, D.N. 1999. Heterosis: Feeding people and protecting natural resources, p. 19-29. In: The genetics and exploitation of heterosis in crops. J.G. Coors and S. Pandey (eds.). ASA-CSSA-SSSA, Madison, Wis.

Frey, K.J. 1996. National plant breeding survey-1. Iowa State Univ., Iowa Agr. and Home Econ. Expt. Stn. Spec. Rpt. 98.

Glover, W.H. 1952. Farm and college. Coll. Agr., Univ. of Wisconsin. Vail-Ballous Press, Binghamton, N.Y.

Goldman, I.L., M.J. Havey, and G. Schroeck. 2001. History of public onion breeding programs in the United States. Plant Breeding Rev. 20:67-103.

Harlan, J.R. 1992. Crops and man. 2nd ed. ASACSSA, Madison, Wis.

Hill, R.R., Jr., J.S. Shenk, and R.F. Barnes. 1988. Breeding for yield and quality, p. 809-825. In: A.A. Hanson et al. (eds.). Alfalfa and alfalfa improvement. Agron. Monogr. 29. Amer. Soc. Agron., Crop Sci. Soc. Amer., Soil Sci. Soc. Amer., Madison, Wis.

Jenkins, J.W. 1991. Acentennial history: A history of the College of Agricultural and Life Sciences at the University of Wisconsin-Madison.

Miller, F.R. and Y. Kebede. 1984. Genetic contributions to yield gains in sorghum, 1950-1980, p. 1-14. In: W.R. Fehr (ed.). Genetic contributions to yield gains of five major crop plants. CSSA Spec. Publ. 7. ASA-CSSA-SSSA, Madison, Wis.

Simon, P.W. 2000. Domestication, historical development, and modern breeding of carrot. Plant Breed. Rev. 19:157-189.

Specht, J.E. and J.H. Williams. 1984. Contribution of genetic technology to soybean productivity - Retrospect and prospect, p. 49-74. In: W.R. Fehr (ed.). Genetic contributions to yield gains of five major crop plants. CSSA Spec. Publ. 7. ASA-CSSA-SSSA, Madison, Wis.

Stare, F.A. 1949. The story of Wisconsin's great canning industry. The canning trade. Baltimore, Md.

Tilman, D., J. Fargione, B. Wolff, C. D'Antonio, A. Dobson, R. Howarth, D. Schindler, W.H. Schlesinger, D. Simberloff, and D. Swackhamer. 2001. Forecasting agriculturally driven global climate change. Science 292:281-284.

Undersander, D., N. Martin, D. Cosgrove, K. Kelling, M. Schmitt, J. Wedberg, R. Becker, C. Grau, J. Doll, and M.E. Rice. 1994. Alfalfa management guide. NCR547. Amer. Soc. Agron., Madison, Wis.

Wycham, R.D. and D.C. Rasmusson. 1983. Genetic improvement in malting barley cultivars since 1920. Crop Sci. 23:1037-1040.

USDAAgricultural Statistics Bulletins. 1900-2000. U.S. Dept. Agr., Washington, D.C.

Wehner, T.C. 1999. Heterosis in vegetable crops, 387-397. In: The genetics and exploitation of heterosis in crops. J.G. Coors and S. Pandey (eds.). ASA-CSSA-SSSA. Madison, Wis.

Wisconsin Agricultural Statistics. Bulletins. 19211999. Wisconsin Agr. Stat. Serv., Madison. 